\title{
Protective mechanism of Korean Red Ginseng in cisplatin-induced ototoxicity through attenuation of nuclear factor- $\kappa B$ and caspase-1 activation
}

\author{
SU-JIN KIM ${ }^{1}$, HYUN JEONG KWAK ${ }^{2}$, DAE-SEUNG KIM ${ }^{3}$, HYUN-MYUNG CHOI ${ }^{2}$, JUNG-EUN SIM ${ }^{2}$, \\ SUNG-HOON KIM ${ }^{2}$, JAE-YOUNG $\mathrm{UM}^{2 *}$ and SEUNG-HEON HONG ${ }^{3 *}$
}

\author{
${ }^{1}$ Department of Cosmeceutical Science, Daegu Hanny University, Kyungsan 712-715; \\ ${ }^{2}$ Department of Pharmacology, College of Korean Medicine, Institute of Korean Medicine, Kyung Hee University, Seoul 130-701; \\ ${ }^{3}$ Department of Oriental Pharmacy, College of Pharmacy, Wonkwang-Oriental Medicines Research Institute, \\ Wonkwang University, Iskan, Jeonbuk 570-749, Republic of Korea
}

Received March 26, 2014; Accepted January 27, 2015

DOI: $10.3892 / \mathrm{mmr} .2015 .3396$

\begin{abstract}
Cisplatin is an effective anti-cancer drug; however, one of its side effects is irreversible sensorineural hearing damage. Korean Red Ginseng (KRG) has been used clinically for the treatment of various diseases; however, the underlying mechanism of KRG treatment of ototoxicity has not been studied extensively. The present study aimed to further investigate the mechanism of KRG on cisplatin-induced toxicity in auditory HEI-OC1 cells in vitro, as well as in vivo. The pharmacological effects of KRG on cisplatin-induced changes in the hearing threshold of mice were determined, as well as the effect on the impairment of hair cell arrays. In addition, in order to elucidate the protective mechanisms of KRG, the regulatory effects of KRG on cisplatin-induced apoptosis-associated gene levels and nuclear factor- $\kappa \mathrm{B}(\mathrm{NF}-\kappa \mathrm{B})$ activation were investigated in auditory cells. The results revealed that KRG prevented cisplatin-induced alterations in the hearing threshold of mice as well as the destruction of hair cell arrays in rat organ of Corti primary explants. In addition, KRG inhibited cisplatin-mediated cell toxicity, reactive oxygen species generation, interleukin-6 production, cytochrome $c$ release and activation of caspases-3
\end{abstract}

Correspondence to: Professor Seung-Heon Hong, Department of Oriental Pharmacy, College of Pharmacy, Wonkwang-Oriental Medicines Research Institute, Wonkwang University, Iskan-dareo 460, Iskan, Jeonbuk 570-749, Republic of Korea

E-mail: jooklim@wku.ac.kr

Professor Jae-Young Um, Department of Pharmacology, College of Korean Medicine, Institute of Korean Medicine, Kyung Hee University, Kyungheedae-ro 26, Dongdaemun-Gu, Seoul 130-701, Republic of Korea

E-mail: jyum@khu.ac.kr

*Contributed equally

Key words: Korean Red Ginseng, cisplatin, auditory cell, nuclear factor- $\kappa \mathrm{B}$, caspase- 1 in the HEI-OC1 auditory cell line. Furthermore, the results demonstrated that KRG inhibited the activation of NF- $\mathrm{KB}$ and caspase-1. In conclusion, these results provided a model for the pharmacological mechanism of KRG and provided evidence for potential therapies against ototoxicity.

\section{Introduction}

Cisplatin is a chemotherapeutic agent, which is commonly used in the treatment of cancer $(1,2)$. However, cisplatin has been shown to induce a number of severe side effects, including peripheral neuropathy and nephrotoxicity. One of the most serious adverse effects of cisplatin treatment is ototoxicity, which is manifested as irreversible sensorineural hearing loss $(3,4)$. Ototoxicity occurs due to cisplatin-induced auditory and vestibular sensory cell apoptosis (5).

Accumulating evidence has indicated that pro-inflammatory cytokines may be involved in cochlear damage (6-10). These cytokines were shown to induce secondary inflammatory responses, including leukocyte infiltration and scar formation. In addition, one study demonstrated that cisplatin induced ototoxicity via the apoptosis of outer hair cells (OHCs) and supporting cells in the organ of Corti, which occurred in parallel with the production and expression of pro-inflammatory cytokines (11). Nuclear factor (NF)- $\mathrm{kB}$ was reported to be involved in the regulation of cell proliferation, survival, angiogenesis, apoptosis and differentiation $(12,13)$. NF- $\mathrm{KB}$ was shown to activate genes inside the nucleus, which are involved in the regulation of apoptosis, the inflammatory response and oxidative stress $(14,15)$. Numerous studies have indicated that NF- $\mathrm{KB}$ may have a significant role in the mediation of hearing loss. Ototoxic stimulants, including noise exposure and ototoxic drugs, were found to induce the activation of NF- $\kappa \mathrm{B}(16,17)$, which results in damage to the cochlear lateral wall via the production of large amounts of reactive oxygen species $(\operatorname{ROS})(18,19)$. Caspase-1, a member of the caspase family characterized by large pro-domains (20), has been reported to be involved in apoptosis and inflammation following activation (21). Caspase-1 activation results in 
inflammation through the generation of pro-inflammatory cytokines (22). In addition, caspase-1 has a significant role in the cisplatin-induced apoptosis of cochlear hair cells and spiral ganglion neurons.

Korean red ginseng (KRG) has previously been used as a supplementary herbal medicine in the treatment of numerous diseases, including inflammation, diabetes and atherosclerosis $(23,24)$. However, the underlying protective mechanisms of KRG in the context of cisplatin have remained to be elucidated. The present study aimed to further investigate the mechanism of KRG in cisplatin-induced toxicity in auditory HEI-OC1 cells. Furthermore, the protective effects of KRG on cisplatin-induced hair cell damage were investigated in the organ of Corti in a rat model.

\section{Materials and methods}

Reagents. Fetal bovine serum (FBS) and high-glucose Dulbecco's modified Eagle's medium (DMEM) were purchased from Gibco-BRL (Grand Island, NY, USA). cis-Diamineplatinum(II) dichloride (cisplatin; cat. no. 479306), paraformaldehyde, Tween ${ }^{\circledR} 20$, avidinperoxidase, Triton X-100 and liquid nitrogen were purchased from Sigma-Aldrich (St. Louis, MO, USA). 10X phosphate-buffered saline was purchased from bioWORLD (Dublin, OH, USA). ABTS was purchased from BD Bioscience (San Diego, CA, USA). Rabbit polyclonal NF- $\kappa B$ (cat. no. sc-7151), mouse monoclonal cytochrome (cyt) $c$ (cat. no. sc-13156), mouse monoclonal $\alpha$-tubulin (cat. no. sc-8035), rabbit polyclonal histone H1 (cat. no. sc-10806) and rabbit polyclonal caspase-3 (cat.no.sc-7148) antibodies (Abs) were obtained from SantaCruz Biotechnology, Inc. (Dallas, TX, USA). Caspase-1, caspase-3 and caspase- 9 colorimetric kits were supplied by R\&D systems, Inc. (Minneapolis, MN, USA). Purified anti-mouse interleukin (IL)-6 (cat. no. 554400), biotinylated IL-6 (cat. no. 554402) and recombinant IL-6 (cat. no. 554401) Abs were obtained from BD-Pharmingen (San Diego, CA, USA). Peroxidase-conjugated AffiniPure goat anti-rabbit immunoglobulin (Ig)G (cat. no. 111-035-003) and peroxidase-conjugated AffiniPure goat anti-mouse IgG (cat. no. 115-035-062) Abs were purchased from Jackson ImmunoResearch Laboratories, Inc. (West Grove, PA, USA). Nonidet P (NP)-40 was purchased from Abcam (Cambridge, UK).

Preparation of $K R G$. KRG was manufactured by the Korea Ginseng Corporation (Seoul, Korea). Extract was prepared by decocting the KRG with boiling distilled water $(100 \mathrm{~g} / \mathrm{l})$. The extraction was decocted for $\sim 3 \mathrm{~h}$, and was subsequently filtered with Labsystem 2 (EMD Millipore, Billerica, MA, USA), lyophilized with a freeze dryer (Ilshin Bio Base Co., Ltd., Yangju, Korea) and stored at $4^{\circ} \mathrm{C}$. Dilutions were made using saline and filtered through a $0.22-\mu \mathrm{m}$ Millex-GS Syringe Filter unit (EMD Millipore). The KRG extracts contained the following seven glycosides, known as ginsenosides (mg/g): $\mathrm{Rg}_{1}$ (2.481), $\mathrm{Rb}_{1}$ (5.481), $\mathrm{Rg}_{3}(\mathrm{~S})$ (0.197), Re (2.975), Rc (2.248), $\mathrm{Rb}_{2}$ (2.175) and $\mathrm{Rb}(0.566)$ (25).

Cell culture. The HEI-OC1 cell line was provided by Dr Federico Kalinec (House Ear Institute, Los Angeles, CA, USA), which was produced as previously described (26).
The passage number of the cells used was five, and to avoid mycoplasmic infection, the provided cell stocks were reconstituted with Mycoplasma Removal Agent (cat. no. 9030500) from MP Biochemicals (Santa Ana, CA, USA). HEI-OC1 cells express multiple molecular markers that are characteristic of the organ of Corti sensory cells, including $\alpha$-thyroid hormone, brain-derived neurotrophic factor, calbindin, calmodulin, Connexin 26, Math 1, Myosin 7a, organ of Corti protein 2, tyrosine kinase receptors $\mathrm{B}$ and $\mathrm{C}$, platelet-derived growth factor receptor and prestin; in addition, HEI-OC1 cells are particularly sensitive to ototoxic drugs (26). These cells were maintained in DMEM supplemented with $10 \% \mathrm{FBS}$ at $33^{\circ} \mathrm{C}$ with $5 \% \mathrm{CO}_{2}$. Cells were treated with various concentrations of $\operatorname{KRG}(0.5,1$ and $2 \mathrm{mg} / \mathrm{ml})$ for $1 \mathrm{~h}$, and subsequently treated with cisplatin $(20 \mu \mathrm{M})$ for $48 \mathrm{~h}$ at $33^{\circ} \mathrm{C}$.

Ethics statement. All animal procedures and experiments were approved by the Animal Care and Use Committee of Wonkwang University (approval no. WKU14-05; Iskan, Korea). All animals were treated humanely and with regard for alleviation of suffering.

Organ of Corti explant culture. The organ culturing procedure was similar to that described previously (27). In brief, two-day-old Sprague Dawley rats ( $\mathrm{n}=5 /$ group; weighing $6.5 \pm 0.5 \mathrm{~g}$ ) were anesthetized with $\mathrm{CO}_{2}$ and sacrificed by decapitation. Subsequently, the cochlea was carefully removed by dissection. The cochlear explants were treated with KRG $(2 \mathrm{mg} / \mathrm{ml})$ for $1 \mathrm{~h}$, and subsequently treated with cisplatin $(30 \mu \mathrm{M})$ for $24 \mathrm{~h}$ at $33^{\circ} \mathrm{C}$. When the experimental treatment was completed, the culture was prepared for histological analysis. The organ of Corti explants were fixed for $15 \mathrm{~min}$ in $2 \%$ paraformaldehyde in PBS. The specimens were rinsed in PBS, incubated in $0.25 \%$ Triton X-100 for 2 min and immersed in tetramethylrhodamine (TRITC)-labeled phalloidin (1:100; Sigma-Aldrich) in PBS for 20 min. Following rinsing with PBS, the specimens were examined using fluorescence microscopy (IX71, Olympus Corporation, Tokyo, Japan) with the appropriate filters for TRITC.

Animal experiment. All experiments were performed using male Balb/c mice (four-weeks-old; weighing 16-18 g), which were housed in stainless steel cages in a temperature controlled $\left(25^{\circ} \mathrm{C}\right)$ room equipped to maintain a 12-h light/dark cycle. The animals were distributed at random into three groups $(\mathrm{n}=5$ per group) and fed a regular diet. Group 1, regarded as the control group, received intraperitoneal (i.p.) injection of $200 \mu \mathrm{l}$ PBS; group 2 was administered cisplatin $(4 \mathrm{mg} / \mathrm{kg})$ via i.p. injection for four consecutive days; and group 3 was orally administered KRG $(200 \mathrm{mg} / \mathrm{kg})$ once a day for four days; and group 4 was orally administered KRG $(200 \mathrm{mg} / \mathrm{kg}) 1 \mathrm{~h}$ prior to i.p injection of cisplatin $(4 \mathrm{mg} / \mathrm{kg}$ ). An auditory brainstem response (ABR) test was subsequently performed to investigate the effect of KRG on hearing function. Following the ABR test, all of the mice were sacrificed by cervical dislocation.

Assessment of hearing function. ABR tests were conducted under ketamine/xylazine (equivalent to $172.4 \mathrm{mg} / \mathrm{kg}$ ketamine and $5.5 \mathrm{mg} / \mathrm{kg}$ xylazine) sedation. The ABR was used to determine the auditory threshold of mice. While under sedation, 
ABR testing was performed on the animals in response to 4 , 8 and $32 \mathrm{kHz}$ tone bursts. A computer-based signal-averaging system (ABR workstation with SigGen software) from Tucker Davis Technologies (Gainesville, FL, USA) was used to compile ABR data. The ABR was recorded using three platinum-iridium needle electrodes $\left(\mathrm{Ambu}^{\circledR}\right.$ Neuroline Disposable Subdermal Needle Electrodes; Cadwell, Kennewick, WA, USA), positioned subdermally over the vertex (positive), mastoid (negative) and dorsum (reference/ground) areas of the animal. Sound was generated through an Etymotic ER-2 earphone (Etymotic Research, Elk Grove Village, IL, USA), which was placed directly in the ear canal. The ABR threshold began at $90 \mathrm{~dB}$ and decreased in $10 \mathrm{~dB}$ steps, and each response was repeated in triplicate.

Cytokine assays. Expression levels of IL-6 in HEI-OCI cells were examined using a modified ELISA. In brief, the ELISA was set up by coating 96-well plates with mouse monoclonal $\mathrm{Ab}$ against IL-6. The coated plates were then washed with PBS containing $0.05 \%$ Tween 20 . All reagents used in this assay were incubated for $2 \mathrm{~h}$ at $37^{\circ} \mathrm{C}$. Recombinant IL-6 was diluted and used as a standard. Standards were diluted 1:1 with diluents (PBS with $10 \%$ FBS) from $10 \mathrm{ng} / \mathrm{ml}$ to $0.34125 \mathrm{ng} / \mathrm{ml}$ and were used to construct the standard curve. Following $2 \mathrm{~h}$ incubation of standards and cell supernants ( $3 \times 10^{5}$ cells/well) at room temperature, the assay plates were sequentially exposed to biotinylated mouse IL- 6 , avidin peroxidase and [2,2'-Azinobis(3-ethylbenzothiazoline-6-sulfonic acid)-diammonium salt] substrate solution containing $30 \% \mathrm{H}_{2} \mathrm{O}_{2}$. The plates were read at a wavelength of $405 \mathrm{~nm}$ using a VersaMax ${ }^{\mathrm{TM}}$ microplate reader (Molecular Devices, Sunnyvale, CA, USA).

Spectrofluorimetric measurement of intracellular ROS production. Intracellular ROS levels in HEI-OCI cells were measured using fluorescent dye, 2',7'-dichlorofluorescein diacetate (DCFH-DA). In the presence of an oxidant, DCFH is converted into a highly fluorescent molecule, 2',7'-dichlorofluorescein (DCF). Cells $\left(3 \times 10^{5}\right.$ cells/well) were treated with $\mathrm{KRG}(0.5,1$ and $2 \mathrm{mg} / \mathrm{ml}$ ) for $1 \mathrm{~h}$, cultured in the presence or absence of cisplatin $(20 \mu \mathrm{M})$ for $48 \mathrm{~h}$ and subsequently incubated with $5 \mu \mathrm{M}$ DCFH-DA for $30 \mathrm{~min}$. The fluorescence intensity was measured using a spectrofluorometer (RF-5301PC; Shimadzu Corp., Kyoto, Japan) at excitation and emission wavelengths of 485 and $538 \mathrm{~nm}$, respectively.

Preparation of cytoplasmic and nuclear extracts. Nuclear and cytoplasmic extracts were prepared as described previously (28). In brief, following activation of the HEI-COI cells (7x10 ${ }^{6}$ cells/well) with cisplatin, they were washed with ice-cold PBS. These cells were resuspended in $60 \mu \mathrm{l}$ buffer A [10 mM Hepes/KOH, $2 \mathrm{mM} \mathrm{MgCl}$, $0.1 \mathrm{mM}$ EDTA, $10 \mathrm{mM} \mathrm{KCl}$, $1 \mathrm{mM}$ dithiothreitol (DTT) and $0.5 \mathrm{mM}$ phenylmethylsulfonyl fluoride (PMSF); $\mathrm{pH}$ 7.9]. The cells were allowed to swell on ice for $15 \mathrm{~min}$, lysed gently with $2.5 \mu \mathrm{l}$ of $10 \% \mathrm{NP}-40$ and centrifuged at $2,000 \mathrm{x}$ g for $10 \mathrm{~min}$ at $4^{\circ} \mathrm{C}$. The supernatant was collected and used as the cytoplasmic extract. The nuclei pellet was resuspended in $40 \mu \mathrm{l}$ of buffer B $(50 \mathrm{mM} \mathrm{HEPES} / \mathrm{KOH}$, $50 \mathrm{mM} \mathrm{KCl}, 300 \mathrm{mM} \mathrm{NaCl}, 0.1 \mathrm{mM}$ EDTA, $10 \%$ glycerol, $1 \mathrm{mM}$ DTT and 0.5 mM PMSF; pH 7.9), left on ice for $20 \mathrm{~min}$,

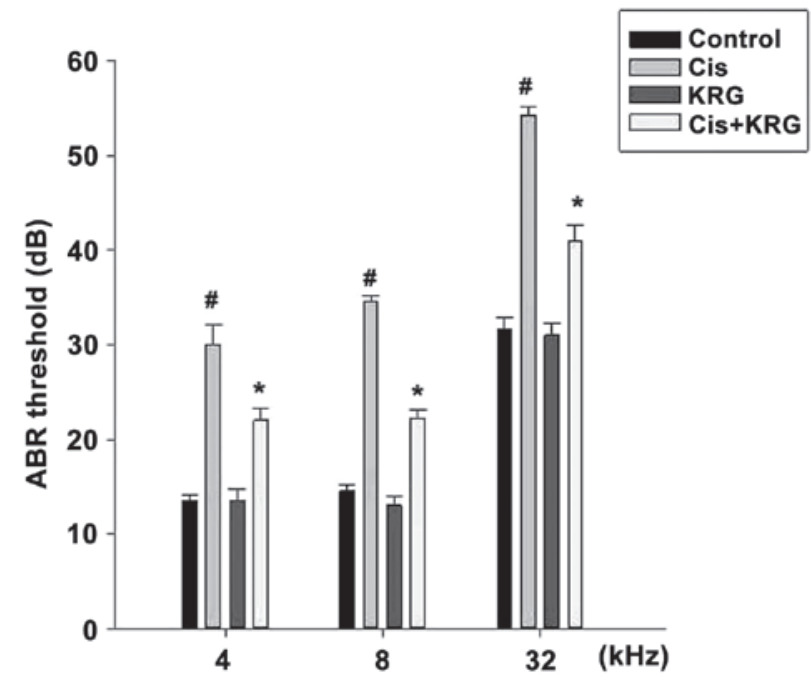

Figure 1. Effect of KRG on cisplatin-induced ABR threshold shift in mice. Mice $(\mathrm{n}=5)$ were orally administered KRG $(200 \mathrm{mg} / \mathrm{kg})$ prior to injection of cisplatin $(4 \mathrm{mg} / \mathrm{kg})$. ABR was used to determine the auditory threshold in response to 4,8 and $32 \mathrm{kHz}$ tone bursts. Values are presented as the mean \pm standard error of the mean of triplicate results from three separate experiments. ${ }^{\text {}} \mathrm{P}<0.05$ vs. control and ${ }^{*} \mathrm{P}<0.05$ vs. cisplatin alone. KRG, Korean Red Ginseng; ABR, auditory brainstem response; Cis, cisplatin.

inverted and centrifuged at $15,000 \mathrm{x} \mathrm{g}$ for $15 \mathrm{~min}$ to remove nuclear debris. The supernatant (nuclear extract) was collected, frozen in liquid nitrogen and stored at $-70^{\circ} \mathrm{C}$ until required for further analysis.

Western blot analysis. For analysis of the expresssion levels of cyt $c$, the cells $\left(5 \times 10^{6}\right.$ cells/well) were rinsed twice with ice-cold PBS and then lysed in ice-cold lysis buffer (1\% Triton, $1 \%$ NP-40, 0.1\% SDS and 1\% deoxycholate in PBS). Samples were centrifuged at $15,000 \mathrm{xg}$ for $5 \mathrm{~min}$ at $4^{\circ} \mathrm{C}$ and the supernatants were mixed with an equal volume of $2 \mathrm{X}$ SDS sample buffer (ELIPIS-Biotech, Inc., Dajeon, Korea), boiled for $5 \mathrm{~min}$ and separated through a $10 \%$ denaturing protein gel. Following electrophoresis, the proteins were transferred to nitrocellulose membranes (GE Healthcare Life Sciences, Uppsala, Sweden) by electrophoretic transfer. The membranes were blocked in 5\% Difco skim milk (BD Diagnostics, Sparks Glencoe, MD, USA) for $2 \mathrm{~h}$, rinsed and incubated overnight at $4^{\circ} \mathrm{C}$ with primary antibodies (1:500). Following three washes (30 min per wash) in PBS/0.5\% Tween 20, the membranes were incubated for $1 \mathrm{~h}$ with horseradish peroxidase-conjugated anti-rabbit immunoglobulin (secondary antibodies). Following three washes (30 min per wash) in PBS/0.1\% Tween 20, the protein bands were visualized using an enhanced chemiluminescence assay (Amersham Pharmacia, Piscataway, NJ, USA) according to the manufacturer's instructions and subsequently exposed to X-ray film (Agfa-Gevaert N.V, Mortsel, Belgium). The relative protein expression levels were evaluated using Image $\mathrm{J}$ software, version 1.48 .

Luciferase assay. Cells were transiently transfected with $\mathrm{NF}-\kappa \mathrm{B}$ luciferase reporter plasmid (Stratagene, Cedar Creek, TX, USA) using the transfection reagent, Lipofectamine 2000 (Invitrogen Life Technologies, Carlsbad, CA, USA). Following 36-h incubation, the cells were treated with various concentrations of 
A

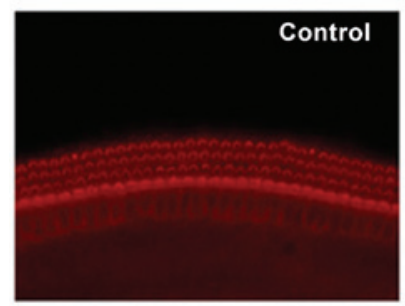

KRG
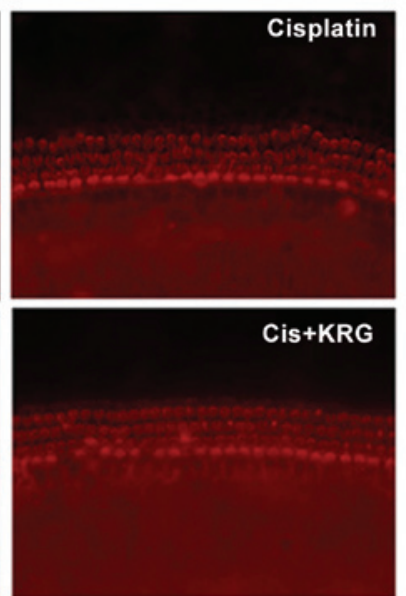

B

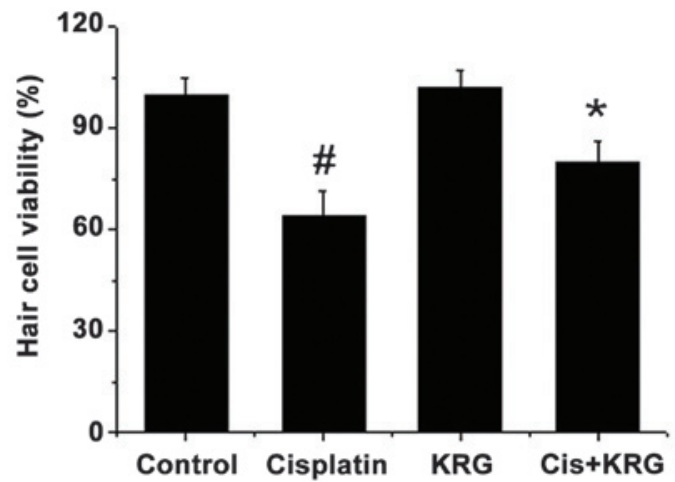

Figure 2. Effect of KRG on cisplatin-induced effects in the organ of Corti in rat primary explants. (A) Explants were pretreated with KRG (2 mg/ml) for $1 \mathrm{~h}$, and then treated with cisplatin. The organ of Corti explants were fixed with paraformaldehyde, stained with tetramethylrhodamine-conjugated phalloidin and observed under a fluorescent microscope (magnification, x200). (B) Relative hair cell viability of each treatment group. Values are presented as the mean \pm standard error of the mean of triplicate determinations from three separate experiments. ${ }^{*} \mathrm{P}<0.05$ vs. control and ${ }^{*} \mathrm{P}<0.05$ vs. cisplatin alone. KRG, Korean Red Ginseng; Cis, cisplatin.

A

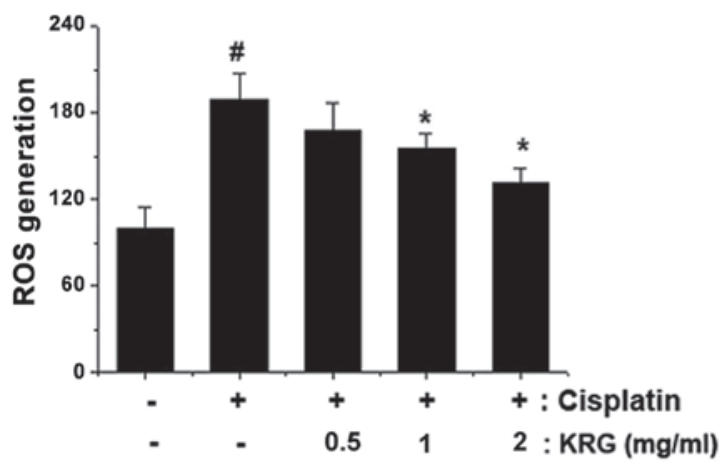

B

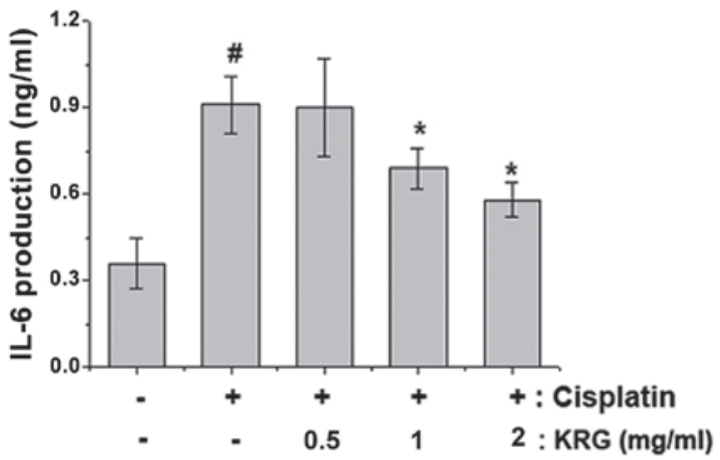

Figure 3. Effect of KRG on cisplatin-induced ROS generation and IL-6 production in HEI-OC1 cells. Cells ( $3 \times 10^{5}$ cells/well) were treated with various concentrations of $\operatorname{KRG}(0.5,1$ and $2 \mathrm{mg} / \mathrm{ml})$ for $1 \mathrm{~h}$ and then treated with cisplatin $(20 \mu \mathrm{M})$ for $48 \mathrm{~h}$. (A) Intracellular ROS levels were determined using a spectrofluorometer and the peroxide-sensitive fluorescent probe, 2',7'-dichlorofluorescein diacetate. (B) IL-6 levels were measured in the cell supernatant using ELISA. Values are presented as the mean \pm standard error of the mean of triplicate determinations from three separate experiments. ${ }^{\sharp} \mathrm{P}<0.05$ vs. control and ${ }^{*} \mathrm{P}<0.05$ vs. cisplatin alone. KRG, Korean Red Ginseng; ROS, reactive oxygen species; IL-6, interleukin 6.

KRG (1 and $2 \mathrm{mg} / \mathrm{ml})$ for $1 \mathrm{~h}$ and then treated with cisplatin $(20 \mu \mathrm{M})$ for $24 \mathrm{~h}$. The cells were then washed twice with PBS buffer and subsequently lysed in reporter lysis buffer (Promega Corporation, Madison, WI, USA). A $20-\mu 1$ aliquot of the lysate was then mixed with $100 \mu \mathrm{l}$ luciferase assay reagent, after which the emitted light intensity was measured using an AutoLumat LB 953 luminometer (Berthold Technologies GmbH \& Co. KG, Bad Wildbad, Germany). Finally, the luciferase activity was measured in triplicate, averaged, and then normalized against the $\beta$-galactosidase activity using the galactosidase assay system (Galacto-Light; Tropix, Inc., Bedford, MA, USA) according to the manufacturer's instructions.

Assay of caspase-1, -3 and -9 activity. The enzymatic activity of caspase-1, -3 and -9 was evaluated using a caspase colorimetric assay kit (R\&D Systems, Inc.) according to the manufacturer's instructions. Cells $\left(5 \times 10^{6}\right.$ cells/well $)$ were treated with various concentrations of $\operatorname{KRG}(0.5,1$ and $2 \mathrm{mg} / \mathrm{ml})$ for $1 \mathrm{~h}$ and then treated with cisplatin $(20 \mu \mathrm{M})$ for $48 \mathrm{~h}$. In brief, the cytoplasmic protein supernatant was incubated with $50 \mu \mathrm{l}$ reaction buffer and $5 \mu \mathrm{l}$ caspase substrate at $37^{\circ} \mathrm{C}$ for $2 \mathrm{~h}$. The absorbance was measured using a plate reader (VersaMax ${ }^{\mathrm{TM}}$ ) at a wavelength of $405 \mathrm{~nm}$. Equal amounts of the total protein from each lysate were quantified using a bicinchoninic acid (BCA) protein quantification kit (Sigma-Aldrich) according to the manufacturer's instructions. Inhibition rate was calculated as follows: Inhibition rate $=[(\mathrm{KRG}$ OD) $-($ control OD) $] /[$ (cisplatin-only OD) - (control OD)]x100\%; where OD stands for optical density.

Statistical analysis. Values are presented as the mean \pm standard error of the mean of at least three independent experiments. Statistical analysis was performed using one-way analysis of variance with Tukey's post hoc test (PASW Statistics 18.0.0.; SPSS Inc., Chicago, IL, USA) $\mathrm{P}<0.05$ was considered to indicate a statistically significant difference between values.

\section{Results}

$K R G$ attenuates cisplatin-induced changes in the hearing threshold of mice. In order to investigate the effect of KRG 
A

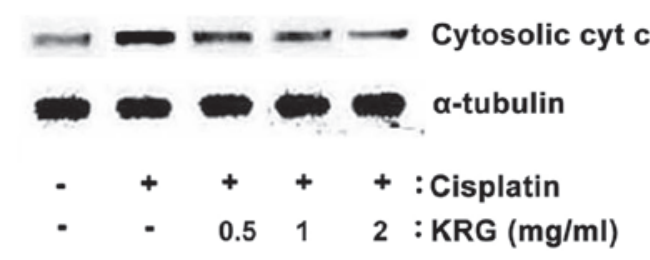

C

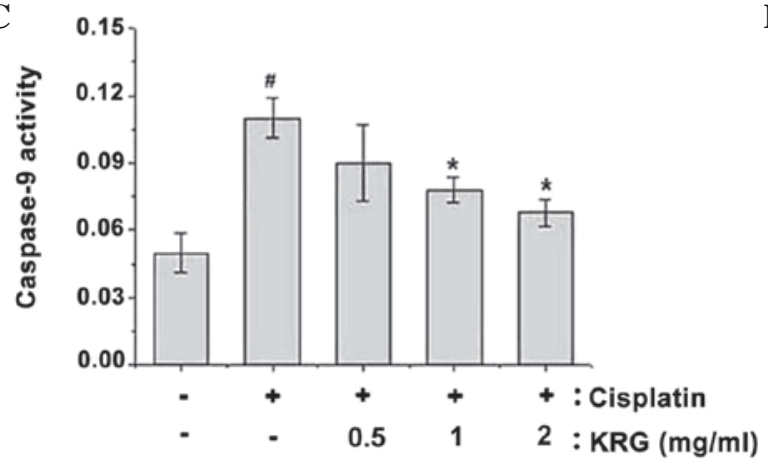

B

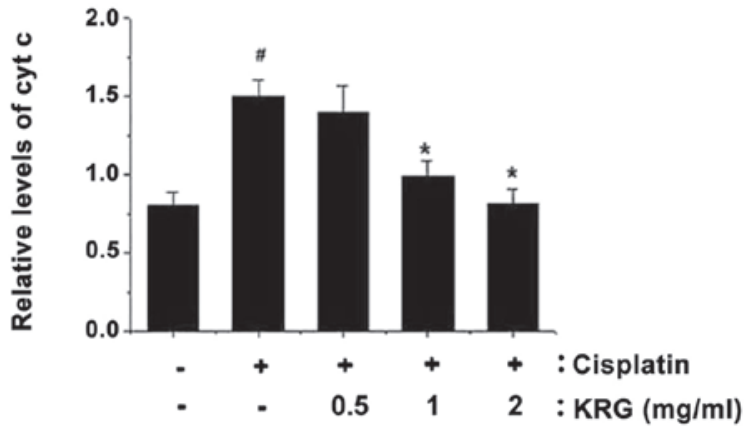

D

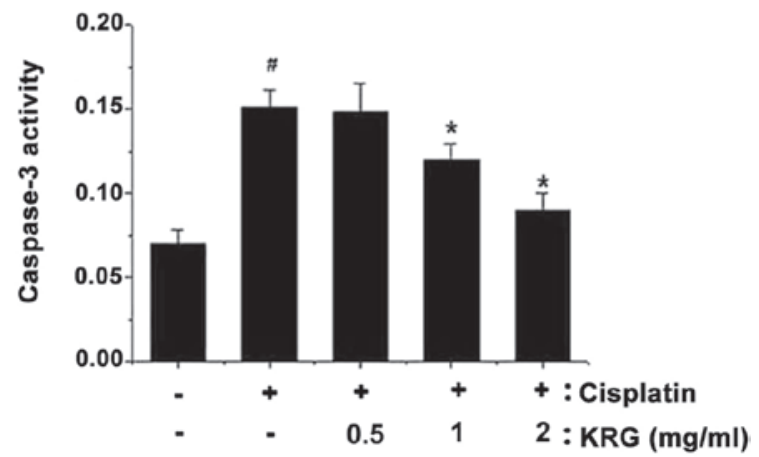

Figure 4. Effect of KRG on cisplatin-induced cyt $c$ release and caspase activation in HEI-OC1 cells. Cells (5x10 6 cells/well) were treated with various concentrations of $\operatorname{KRG}(0.5,1$ and $2 \mathrm{mg} / \mathrm{ml})$ for $1 \mathrm{~h}$ and then treated with cisplatin $(20 \mu \mathrm{M})$ for $48 \mathrm{~h}$. (A) Following isolation of the cytoplasmic fraction, cyt $c$ was measured in the protein extracts using western blot analysis. $\alpha$-tubulin was used as the loading control. (B) Relative expression level of cyt $c$ was measured using an image analyzer. Activity of (C) caspase- 9 and (D) caspase- 3 was determined using a colorimetric kit. Values are presented as the mean \pm standard error of the mean of triplicate determinations from three separate experiments. Relative protein levels were determined using the amount of $\alpha$-tubulin reference protein in each condition, and band intensities were measured using the Image J 1.48 software. ${ }^{\#} \mathrm{P}<0.05$ vs. control and "P<0.05 vs. cisplatin alone. KRG, Korean Red Ginseng; cyt $c$, cytochrome $c$.

on hearing function, ABR was recorded at 4,8 and $32 \mathrm{kHz}$. The results indicated that the cisplatin-only group had a significantly increased ABR threshold shift at 4,8 and $32 \mathrm{kHz}$ compared with that of the control group $(\mathrm{P}<0.05)$. However, KRG (200 mg/kg) was shown to significantly attenuate the cisplatin-induced hearing threshold shift (Fig. 1).

$K R G$ attenuates cisplatin-induced toxicity in organ of Corti explants. The organ of Corti was isolated from rats on postnatal day two and treated with cisplatin $(30 \mu \mathrm{M})$ in presence of KRG (2 mg/ml). As indicated in Fig. 2A, cisplatin treatment impaired the orderly arrangements of the three rows of $\mathrm{OHCs}$ and a single row of inner hair cells (IHCs) in the organ of Corti. However, treatment with KRG in combination with cisplatin significantly attenuated this effect $(\mathrm{P}<0.05)$. The relative hair cell viability is presented in Fig. $2 \mathrm{~B}$, and indicates a significant decrease in hair cell viability in the cisplatin-treated group, compared with that of the control group $(\mathrm{P}<0.05)$ that is attenuated following KRG pretreatment $(\mathrm{P}<0.05)$.

KRG suppresses the cisplatin-induced increase in IL-6 levels and ROS generation in HEI-OCl cells. ROS generated in the mitochondria may induce damage to the mitochondrial membrane, resulting in apoptosis (29). In order to determine the regulatory effects of KRG on ROS production, cells were treated with DCFH-DA, which is converted to a fluorescent substance following intracellular oxidation. The results revealed that KRG effectively suppressed the significant increase in ROS levels induced by cisplatin treatment $(\mathrm{P}<0.05$; Fig. 3A).
Previous studies have reported that the expression of inflammatory cytokines is significantly enhanced in the inner ear under various damaging conditions (30-33). In order to determine whether $\mathrm{KRG}$ was able to regulate the enhanced IL-6 levels induced by cisplatin, ELISAs were performed. As shown in Fig. 3B, IL-6 levels were significantly increased following treatment with cisplatin compared with those of the control group $(\mathrm{P}<0.05)$; however, this effect was markedly reduced following treatment with KRG $(\mathrm{P}<0.05)$.

$K R G$ inhibits the increased apoptosis-associated gene levels induced by cisplatin in HEI-OCI cells. Pro-apoptotic stimuli induce the release of cyt $c$ into the cytosol, which leads to the activation of pro-apoptotic factors as well as the maturation of caspase-3 (34,35). As shown in Fig. 4A and B, the effect of KRG on cisplatin-induced cyt $c$ release was examined. The results revealed that cisplatin significantly increased the quantity of cyt $c$ released into the cytosol compared with that of the control group $(\mathrm{P}<0.05)$; however, $\mathrm{KRG}$ significantly inhibited cisplatin-induced cyt $c$ release $(\mathrm{P}<0.05)$.

Caspase-3 is known to have a significant role in the initiation and implementation of apoptosis $(36,37)$. In the present study, the inhibitory effect of KRG on caspase- 9 and caspase- 3 activity was examined. Cisplatin significantly induced caspase-9 and caspase-3 activation compared with that of the control group $(\mathrm{P}<0.05)$, while KRG effectively inhibited this induction $(\mathrm{P}<0.05)$ (Fig. 4C and 4D).

$K R G$ inhibits cisplatin-induced $N F-\kappa B$ activation in HEI-OCI cells. Reduced NF- $\kappa \mathrm{B}$ activation has previously been associated 

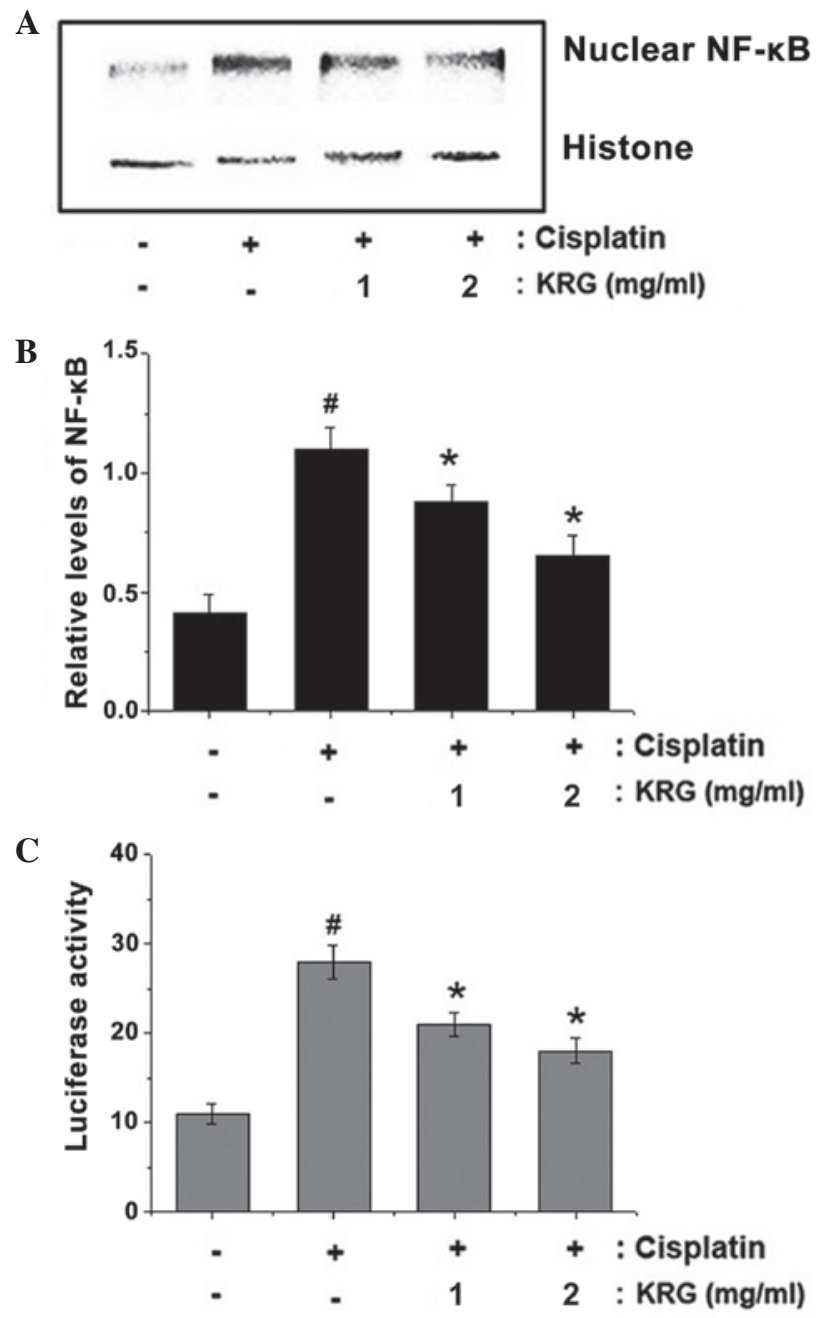

Figure 5. Effect of KRG on cisplatin-induced NF- $\kappa B$ activation in HEI-COI cells. Cells $\left(7 \times 10^{6}\right.$ cells/well) were treated with various concentrations of KRG (1 and $2 \mathrm{mg} / \mathrm{ml})$ for $1 \mathrm{~h}$ and then treated with cisplatin $(20 \mu \mathrm{M})$ for $24 \mathrm{~h}$. (A) Following isolation of the nuclear fraction, the NF-kB protein levels were determined using western blot analysis. (B) Relative protein expression of NF- $\mathrm{KB}$. (C) NF- $\mathrm{KB}$ activity was examined using a luciferase assay. Values are presented as the mean \pm standard error of the mean of triplicate determinations from three separate experiments. Relative protein levels were determined using the amount of Histone reference protein in each condition, and band intensities were measured using the Image $\mathrm{J} 1.48$ software. ${ }^{*} \mathrm{P}<0.05$ vs. control and ${ }^{*} \mathrm{P}<0.05$ vs. cisplatin alone. KRG, Korean Red Ginseng; NF- $\kappa \mathrm{B}$, nuclear factor $\kappa \mathrm{B}$.

with hearing loss $(38,39)$; therefore, it was hypothesized that the effects of KRG may be mediated, at least in part, by the suppression of NF- $\kappa B$ activation. In addition, NF- $\mathrm{kB}$ activation requires the nuclear translocation of the RelA/p65 subunit of NF- $\mathrm{KB}$ (40); therefore, the present study aimed to evaluate the effects of KRG on the nuclear pool of RelA/p65 protein using western blot analysis. In cisplatin-treated cells, the levels of Rel/p65 were markedly increased compared with those of the untreated group; however, KRG reduced these enhanced nuclear levels of Rel/p65 (Fig. 5A). The relative nuclear levels of NF- $\kappa \mathrm{B}$ are exhibited in Fig. 5B. The cisplatin-induced increase in NF- $\kappa \mathrm{B}$ expression was significantly attenuated following KRG pretreatment in a dose-dependent manner.

Furthermore, a luciferase assay was performed in order to investigate the effects of $\mathrm{KRG}$ on $\mathrm{NF}-\mathrm{\kappa B}$ promoter activity. As shown in Fig. 5C, cisplatin treatment enhanced NF- $\mathrm{\kappa B}$ promoter

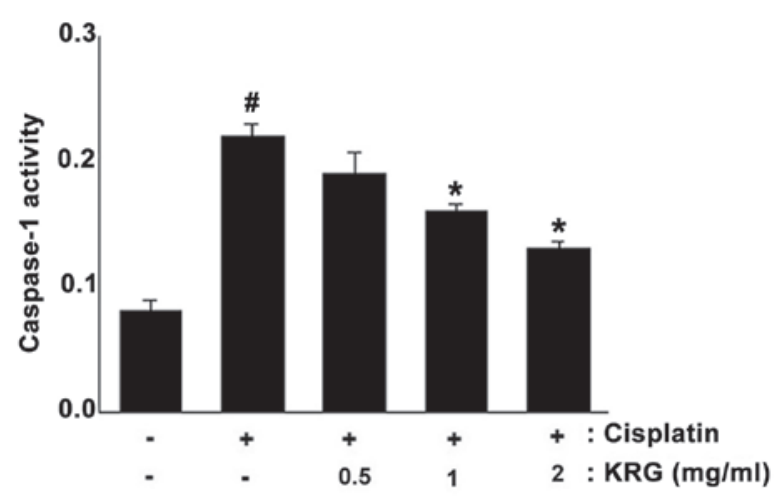

Figure 6. Effect of KRG on cisplatin-induced caspase-1 activation in HEI-COI cells. Cells $\left(5 \times 10^{6}\right.$ cells/well) were treated with various concentrations of $\operatorname{KRG}(0.5,1$ and $2 \mathrm{mg} / \mathrm{ml})$ for $1 \mathrm{~h}$ and then treated with cisplatin $(20 \mu \mathrm{M})$ for $48 \mathrm{~h}$. The activity of caspase- 1 was determined using a colorimetric kit. Values are presented as the mean \pm standard error of the mean of triplicate determinations from three separate experiments. ${ }^{\#} \mathrm{P}<0.05$ vs. control and ${ }^{*} \mathrm{P}<0.05$ vs. cisplatin alone. KRG, Korean Red Ginseng.

activity compared with that of the control group $(\mathrm{P}<0.05)$, while KRG treatment inhibited this cisplatin-induced increase in NF- $\mathrm{KB}$ promoter activity $(\mathrm{P}<0.05)$.

KRG attenuates cisplatin-induced caspase-1 activation in HEI-OCI cells. The activation of caspase-1 induces the activation of NF- $\mathrm{KB}$ and production of inflammatory cytokines (41). In order to elucidate the mechanism underlying the protective effects of KRG on ototoxicity, the effects of KRG on caspase-1 activation were evaluated. The results demonstrated that the enhanced caspase-1 activity induced by cisplatin was significantly reduced by KRG in a dose-dependent manner $(\mathrm{P}<0.05)$ (Fig. 6). The maximal inhibition rate of KRG $(2 \mathrm{mg} / \mathrm{ml})$ was $42.21 \pm 3.1 \%$ compared with that of the cisplatin-only group.

\section{Discussion}

KRG has been reported to have numerous beneficial therapeutic effects including anti-cancer, anti-inflammatory and anti-oxidant activities (42). However, the underlying protective mechanisms of KRG in the auditory system have remained to be fully elucidated. The results of the present study demonstrated that KRG attenuated the adverse effects of cisplatin in the organ of Corti as well as apoptosis in auditory cells.

Cisplatin is an effective, commonly used anticancer agent; however, its major side effects include hearing damage. A previous study investigated the mechanisms underlying cisplatin-induced ototoxicity (43). The results of the present study demonstrated that KRG pretreatment effectively prevented cisplatin-induced impairment of hair cell arrays in the rat organ of Corti primary explants. Cisplatin has been confirmed to induce the apoptosis of auditory sensory cells (44). The mitochondrial apoptotic pathway has been demonstrated to be activated by the release of proteins from the mitochondrial intermembrane space into the cytosol, which subsequently initiate the activation of apoptotic pathways (44). Cyt $c$ is a mitochondrial protein, which induces caspase-dependent cell apoptotsis; cyt $c$ initiates caspase-9 activation, which in turn activates caspase-3 (45). It was 
reported that cisplatin-mediated ototoxicity was associated with caspase-3 activity, cyt $c$ release and ROS generation in auditory cells $(46,47)$. These previous studies therefore indicated that mitochondrial signaling pathways may represent potential therapeutic targets for use in the prevention of cisplatin-mediated ototoxic damage. In the present study, KRG was demonstrated to inhibit the cyt $c$ release, ROS generation and caspase- 3 activation induced by cisplatin. These results therefore suggested that the protective effect of KRG in auditory cells occurred via the regulation of caspase-mediated apoptosis. Although KRG attenuated the caspase-mediated pathway, the present study did not investigate the effects of KRG on non-mitochondrial signaling pathways. Therefore, further studies are required in order to evaluate the potential role of KRG on non-mitochondrial signaling pathways in the auditory system.

Numerous previous studies have reported that inflammatory cytokines are associated with hearing loss (7-10,32). These cytokines were reported to induce secondary inflammatory responses, including leukocyte infiltration and scar formation. In addition, it was reported that cisplatin-induced cochlear injury occured via pro-inflammatory cytokine expression (11). Flunarizine, a T-type $\mathrm{Ca}^{2+}$ channel antagonist, was demonstrated to have cyto-protective effects against cisplatin cytotoxicity, the mechanism of which was shown to proceed via the inhibition of pro-inflammatory cytokine expression in HEI-OC1 cells (46). It was therefore hypothesized that the protective effect of KRG may occur via the regulation of pro-inflammatory cytokines. In the present study, it was demonstrated that KRG inhibited IL-6 expression levels, which indicated that the protective effect of KRG against cisplatin cytotoxicity occurred due to the suppression of inflammatory cytokine levels in auditory cells. Although it was demonstrated that KRG attenuated IL-6 expression levels, the effects of KRG on other cytokine pathways, or any pathways that may be involved, were not evaluated. Therefore, further studies are required in order to clarify the role of KRG in the cytokine-associated pathways in the auditory system.

The association between NF- $\mathrm{\kappa B}$ activation and hearing loss has been investigated in numerous previous studies $(38,39,48)$. Certain studies have reported that NF- $\mathrm{KB}$ family proteins identified in the inner ear were essential for the regular function of hair cells (49), while other studies have demonstrated that signal-transduction pathways respond rapidly to ototoxic stimulants, including noise exposure (38) and ototoxic drugs $(16,50,51)$. NF- $\mathrm{kB}$ activation was reported to induce damage to the cochlear lateral wall through the generation of large quantities of ROS (52). In addition, acoustic overstimulation enhances inflammatory factor expression levels via NF- $\mathrm{kB}$ activation in the inner ear (39). The results of these studies suggested that NF- $\mathrm{\kappa B}$ activation may be the primary target for the prevention of cisplatin-induced ototoxic damage. Therefore, in the present study, whether the protective mechanism of KRG proceeded via NF- $\kappa \mathrm{B}$ pathway regulation was investigated. The results revealed that KRG attenuated the cisplatin-induced activation of NF- $\mathrm{kB}$ in auditory cells.

The activation of caspase-1 is known to be involved in the mediation of apoptosis and inflammation (21). Activated caspase-1 induces inhibitor of $\kappa \mathrm{B}$ (IкB) kinase (IKK) phosphorylation by RIP2 dependent pathway. Caspase-1 interacts with RIP2 through the caspase recruitment domain, then RIP2 recruits the IKK complex via interaction with IKK- $\gamma$. This is independent of the enzymatic activity of caspase-1, and results in I $\kappa \mathrm{B}-\alpha$ degradation and NF- $\kappa \mathrm{B}$ activation (41). Therefore, released NF- $\kappa \mathrm{B}$ is translocated to the nucleus, where it is involved in the induction of gene transcription (53). The addition of pro-inflammatory cytokines, including IL- $1 \beta$, has previously been shown to increase the nuclear translocation of NF- $\mathrm{KB}$ in HEI-OC1 auditory cells (11). Caspase-1 may contribute to NF- $\kappa B$ activation via the autocrine action of IL- $1 \beta$. Therefore, it was hypothesized that the NF- $\mathrm{BB}$ pathway may interact with caspase-1 in auditory cells. Zhang et al (54) reported that caspase-1 initiated cyt $c$ release and caspase-3 activation in ischemia/hypoxia-mediated neuronal cell death. In addition, it was demonstrated that cisplatin induced caspase-1 activation in cochlear hair cells and spiral ganglion neurons (55). In the present study, KRG was found to inhibit cisplatin-induced caspase-1 activation. These results suggested that the protective mechanism of KRG may be mediated via the modulation of signaling molecules involved cisplatin-induced apoptosis.

In conclusion, KRG was demonstrated to attenuate ototoxicity through prevention of the impairment of the hair cell arrays in organ of Corti rat primary explants. In addition, KRG inhibited cisplatin-induced ROS production, enhanced IL-6 levels, cyt $c$ release, caspase- 3 activation and NF- $\mathrm{KB}$ translocation to the nucleus in auditory cells. Therefore, these results have contributed to the elucidation of the pharmacological mechanism underlying KRG function and have provided evidence for potential therapeutic approaches for the treatment of ototoxicity.

\section{Acknowledgements}

The present study was supported by the National Research Foundation of Korea grants funded by the Korean government (no. 2011-0006220).

\section{References}

1. Cohen SM and Lippard SJ: Cisplatin: from DNA damage to cancer chemotherapy. Prog Nucleic Acid Res Mol Biol 67: 93-130, 2001.

2. Santos NA, Catão CS, Martins NM, Curti C, Bianchi ML and Santos AC: Cisplatin-induced nephrotoxicity is associated with oxidative stress, redox state unbalance, impairment of energetic metabolism and apoptosis in rat kidney mitochondria. Arch Toxicol 81: 495-504, 2007.

3. Yao X, Panichpisal K, Kurtzman N and Nugent K: Cisplatin nephrotoxicity: a review. Am J Med Sci 334: 115-124, 2007.

4. Yu YN, Chen H and Li Yi: Protect effect of bicyclol on cisplatin-induced nephrotoxicity in mice. Arch Toxicol 83: 381-387, 2009.

5. Jordan P and Carmo-Fonseca M: Molecular mechanisms involved in cisplatin cytotoxicity. Cell Mol Life Sci 57: 1229-1235, 2000.

6. Satoh H, Firestein GS, Billings PB, Harris JP and Keithley EM: Proinflammatory cytokine expression in the endolymphatic sac during inner ear inflammation. J Assoc Res Otolaryngol 4: $139-147,2003$.

7. Keithley EM, Wang X and Barkdull GC: Tumor necrosis factor alpha can induce recruitment of inflammatory cells to the cochlea. Otol Neurotol 29: 854-859, 2008.

8. Wakabayashi K, Fujioka M, Kanzaki S, et al: Blockade of interleukin-6 signaling suppressed cochlear inflammatory response and improved hearing impairment in noise-damaged mice cochlea. Neurosci Res 66: 345-352, 2010.

9. Oh GS, Kim HJ, Choi JH, et al: Activation of lipopolysaccharide-TLR4 signaling accelerates the ototoxic potential of cisplatin in mice. J Immunol 186: 1140-1150, 2011. 
10. Kim HJ, Oh GS, Lee JH, et al: Cisplatin ototoxicity involves cytokines and STAT6 signaling network. Cell Res 21: 944-956, 2011.

11. So H, Kim H, Lee JH, et al: Cisplatin cytotoxicity of auditory cells requires secretions of proinflammatory cytokines via activation of ERK and NF-kappaB. J Assoc Res Otolaryngol 8: 338-355, 2007.

12. Bharti AC, Donato N, Singh S and Aggarwal BB: Curcumin (diferuloylmethane) down-regulates the constitutive activation of nuclear factor-kappaB and IkappaBalpha kinase in human multiple myeloma cells, leading to suppression of proliferation and induction of apoptosis. Blood 101: 1053-1062, 2003.

13. Estrov Z, Shishodia S, Faderl S, et al: Resveratrol blocks interleukin-1 $\beta$-induced activation of the nuclear transcription factor $N F-\kappa B$, inhibits proliferation, causes $S$-phase arrest and induces apoptosis of acute myeloid leukemia cells. Blood 102: 987-995, 2003.

14. Christman JW, Sadikot RT and Blackwell TS: The role of nuclear factor- $\kappa \mathrm{B}$ in pulmonary diseases. Chest 117: 1482-1487, 2000.

15. Janssen-Heininger YM, Poynter ME and Baeuerle PA: Recent advances towards understanding redox mechanisms in the activation of nuclear factor kappaB. Free Radic Biol Med 28: $1317-1327,2000$

16. Jiang $\mathrm{H}$, Sha SH and Schacht J: NF- $\kappa B$ pathway protects cochlear hair cells from aminoglycoside-induced ototoxicity. J Neurosci Res 79: 644-651, 2005.

17. Nagashima R, Sugiyama C, Yoneyama M, Kuramoto N, Kawada K and Ogita K: Acoustic overstimulation facilitates the expression of glutamate-cysteine ligase catalytic subunit probably through enhanced DNA binding of activator protein-1 and/or NF- $\kappa \mathrm{B}$ in the murine cochlea. Neurochem Int 51: 209-215, 2007.

18. Shi $X$ and Nuttall AL: Expression of adhesion molecular proteins in the cochlear lateral wall of normal and PARP-1 mutant mice. Hear Res 224: 1-14, 2007.

19. Masuda M, Nagashima R, Kanzaki S, Fujioka M, Ogita K and Ogawa K: Nuclear factor-kappaB nuclear translocation in the cochlea of mice following acoustic overstimulation. Brain Res 1068: 237-247, 2006.

20. Lee SH, Stehlik C and Reed JC: Cop, a caspase recruitment domain-containing protein and inhibitor of caspase-1 activation processing. J Biol Chem 276: 34495-34500, 2001.

21. Wang X, Wang H, Figueroa BE, et al: Dysregulation of receptor interacting protein-2 and caspase recruitment domain only protein mediates aberrant caspase-1 activation in Huntington's disease. J Neurosci 25: 11645-11654, 2005.

22. Faubel S, Lewis EC, Reznikov L, et al: Cisplatin-induced acute renal failure is associated with an increase in the cytokines interleukin (IL)-1beta, IL-18, IL-6 and neutrophil infiltration in the kidney. J Pharmacol Exp Ther 322: 8-15, 2007.

23. Sung J, Han KH, Zo JH, Park HJ, Kim CH and Oh BH: Effects of red ginseng upon vascular endothelial function in patients with essential hypertension. Am J Chin Med 28: 205-216, 2000.

24. Ryu JK, Lee T, Kim DJ, et al: Free radical-scavenging activity of Korean red ginseng for erectile dysfunction in non-insulin-dependent diabetes mellitus rats. Urology 65: 611-615, 2005.

25. Hong SH, Suk KT, Choi SH, et al: Anti-oxidant and natural killer cell activity of Korean red ginseng (Panax ginseng) and urushiol (Rhus vernicifera Stokes) on non-alcoholic fatty liver disease of rat. Food Chem Toxicol 55: 586-591, 2013.

26. Kalinec GM, Webster P, Lim DJ and Kalinec F: A cochlear cell line as an in vitro system for drug ototoxicity screening. Audiol Neurootol 8: 177-189, 2003

27. Zheng JL and Gao WQ: Differential damage to auditory neurons and hair cells by ototoxins and neuroprotection by specific neurotrophins in rat cochlear organotypic cultures. Eur J Neurosci 8: 1897-1905, 1996.

28. Schoonbroodt S, Legrand-Poels S, Best-Belpomme $M$ and Piette J: Activation of the NF-kappaB transcription factor in a T-lymphocytic cell line by hypochlorous acid. Biochem J 321: 777-785, 1997.

29. Orrenius S: Reactive oxygen species in mitochondria-mediated cell death. Drug Metab Rev 39: 443-455, 2007.

30. Fujioka M,Kanzaki S, Okano HJ, Masuda M, Ogawa K and Okano $\mathrm{H}$ : Proinflammatory cytokines expression in noise-induced damaged cochlea. J Neurosci Res 83: 575-583, 2006.

31. Ghaheri BA, Kempton JB, Pillers DA and Trune DR: Cochlear cytokine gene expression in murine acute otitis media. Laryngoscope 117: 22-29, 2007.
32. Kim HJ, So HS, Lee JH, et al: Role of proinflammatory cytokines in cisplatin-induced vestibular hair cell damage. Head Neck 30: 1445-1456, 2008.

33. Ladrech S, Mathieu M, Puel JL and Lenoir M: Supporting cells regulate the remodelling of aminoglycoside-injured organ of Corti, through the release of high mobility group box 1 . Eur J Neurosci 38: 2962-2972, 2013.

34. Gorman AM, Bonfoco E, Zhivotovsky B, Orrenius S and Ceccatelli S: Cytochrome $c$ release and caspase-3 activation during colchicine-induced apoptosis of cerebellar granule cells. Eur J Neurosci 11: 1067-1072, 1999.

35. Abu-Qare AW and Abou-Donia MB: Biomarkers of apoptosis: release of cytochrome $c$, activation of caspase-3, induction of 8-hydroxy-2'-deoxyguanosine, increased 3-nitrotyrosine, and alteration of p53 gene. J Toxicol Environ Health B Crit Rev 4: 313-332, 2001.

36. Brentnall M, Rodriguez-Menocal L, De Guevara RL, Cepero E and Boise LH: Caspase-9, caspase-3 and caspase-7 have distinct roles during intrinsic apoptosis. BMC Cell Biol 14: 32, 2013.

37. Porter AG and Jänicke RU: Emerging roles of caspase- 3 in apoptosis. Cell Death Differ 6: 99-104, 1999.

38. Lang H, Schulte BA, Zhou D, Smythe N, Spicer SS and Schmiedt RA: Nuclear factor kappaB deficiency is associated with auditory nerve degeneration and increased noise-induced hearing loss. J Neurosci 26: 3541-3550, 2006.

39. Yamamoto H, Omelchenko I, Shi X and Nuttall AL: The influence of NF- $\kappa \mathrm{B}$ signal-transduction pathways on the murine inner ear by acoustic overstimulation. J Neurosci Res 87: 1832-1840, 2009.

40. Stark LA and Dunlop MG: Nucleolar sequestration of RelA (p65) regulates NF-kappaB-driven transcription and apoptosis. Mol Cell Biol 25: 5985-6004, 2005.

41. Lamkanfi M, Kalai M, Saelens X, Declerq W and Vandenabeele P: Caspase-1 activates nuclear factor of the kappa-enhancer in B cells independently of its enzymatic activity. J Biol Chem 279: 24785-24793, 2004.

42. Park K-S, Hwang D-S, Lee J-M, Jang J-B, Lee K-S and Lee C-H: Inhibitory effect of Panax ginseng C. A. Meyer on gynecological cancer. Orient Pharm Exp Med 13: 217-223, 2013.

43. Rybak LP, Whitworth CA, Mukherjea D and Ramkumar V: Mechanisms of cisplatin-induced ototoxicity and prevention. Hear Res 226: 157-167, 2007.

44. Devarajan P, Savoca M, Castaneda MP, et al: Cisplatin-induced apoptosis in auditory cells: role of death receptor and mitochondrial pathways. Hear Res 174: 45-54, 2002.

45. Roy S, Banerjee B and Vedasiromoni J: Anti-tumor activity of Swietenia mahagoni (L.) Jacq. leaf extract against Ehrlich's ascites carcinoma in mice. Orient Pharm Exp Med 13: 205-216, 2013.

46. So HS, Park C, Kim HJ, et al: Protective effect of T-type calcium channel blocker flunarizine on cisplatin-induced death of auditory cells. Hear Res 204: 127-139, 2005.

47. Lee S, Moon SO, Kim W, et al: Protective role of L-2-oxothiazolidine-4-carboxylic acid in cisplatin-induced renal injury. Nephrol Dial Transplant 21: 2085-2095, 2006.

48. Tahera Y, Meltser I, Johansson P, et al: NF-kappaB mediated glucocorticoid response in the inner ear after acoustic trauma. J Neurosci Res 83: 1066-1076, 2006.

49. Shishodia S and Aggarwal BB: Nuclear factor-kappaB: a friend or a foe in cancer? Biochem Pharmacol 68: 1071-1080, 2004.

50. Nagy I, Monge A, Albinger-Hegyi A, Schmid S and Bodmer D: NF-kappaB is required for survival of immature auditory hair cells in vitro. J Assoc Res Otolaryngol 6: 260-268, 2005.

51. Kim SJ, Jeong HJ, Myung NY, et al: The protective mechanism of antioxidants in cadmium-induced ototoxicity in vitro and in vivo. Environ Health Perspect 116: 854-862, 2008.

52. Watanabe K, Inai S, Jinnouchi K, et al: Nuclear-factor kappaB (NF-kappaB)-inducible nitric oxide synthase (iNOS/NOS II) pathway damages the stria vascularis in cisplatin-treated mice. Anticancer Res 22: 4081-4085, 2002.

53. Chu SH, Lim JW, Kim DG, Lee ES, Kim KH and Kim H: Down-regulation of Bcl-2 is mediated by NF- $\kappa \mathrm{B}$ activation in Helicobacter pylori-induced apoptosis of gastric epithelial cells. Scand J Gastroenterol 46: 148-155, 2011.

54. Zhang WH, Wang X, Narayanan M, et al: Fundamental role of the Rip2/caspase-1 pathway in hypoxia and ischemia-induced neuronal cell death. Proc Natl Acad Sci USA 100: 16012-16017, 2003.

55. Liu W, Staecker H, Stupak H, Malgrange B, Lefebvre P and Van De Water TR: Caspase inhibitors prevent cisplatin-induced apoptosis of auditory sensory cells. Neuroreport 9: 2609-2614, 1998. 